\title{
Increased Short-Term and Mid-Term Major Complications Were Observed in Elderly Patients with Renal Dysfunction after Surgical Ventricular Restoration
}

\author{
Fei Xu, MD, Yangwu Song, MD, Wei Feng, MD, Xuan Li, MD, Junzhe Du, MD \\ Department of Cardiovascular Surgery, Fuwai Hospital Chinese Academy of Medical Sciences, Beijing, China
}

\section{ABSTRACT}

Background: This study was conducted to explore the impact of renal dysfunction on short-term and mid-term outcomes in elderly patients.

Methods: Patients over 65 years of age receiving surgical ventricular restoration (SVR) were included in the study. They were stratified through estimated glomerular filtration rate (eGFR), with a cutoff point of $60 \mathrm{~mL} / \mathrm{min} / 1.73 \mathrm{~m}^{2}$. Riskadjusted analysis, including propensity score matching, was carried out to compare short-term and mid-term outcomes between the two groups of patients.

Results: From January 1999 to December 2015, a total of 280 elderly patients underwent SVR. Of the patients, 79 had eGFR lower than $60 \mathrm{~mL} / \mathrm{min} / 1.73 \mathrm{~m}^{2}$ and were considered to have renal dysfunction. Mortality was higher in the renal dysfunction group than the normal renal function group, with marginal significance (adjusted $P$ value $=.06$ ). The need for mechanical supports (adjusted $P$ value $=.04$ ) was higher in the renal dysfunction group. Hemofiltration (adjusted $P$ value $<.01$ ) and requirements for transfusion (adjusted $P$ value $=.03)$ were significantly higher in the renal dysfunction group than in the group with normal renal function. The presence of renal dysfunction was associated with higher risk of major adverse cerebro-cardiovascular events (MACCE) than normal renal function $(\mathrm{HR}=2.34,95 \% \mathrm{CI}=1.34-4.08, P=.003)$.

Conclusion: Compared to patients with normal renal function, elderly SVR patients with renal failure have a higher incidence of short-term mechanical support, mid-term mortality, and MACCE events.

\section{INTRODUCTION}

Chronic ischemic cardiomyopathy lays a heavy burden on health systems worldwide [Moran 2014; Jessup 2003]. When compared with their younger counterparts, elderly patients with coronary heart disease are more susceptible to heart failure, and according to the literature, elderly patients account for more than one-third of those with ischemic cardiomyopathy [Wong 2014; Shafazand 2009]. In fact, chronic

Received September 14, 2017; received in revised form February 23, 2018; accepted February 27, 2018.

Correspondence: Wei Feng, MD, Department of Cardiovascular Surgery, Fuwai Hospital Chinese Academy of Medical Sciences, No.167 North Lishi Road, Xicheng District, Beijing, China; +86-138-0101-8685 (e-mail: fengwei@fuwai.com). ischemic cardiomyopathy is not only risky, but also resource consuming, representing a serious medical issue [Moran 2014]. There are a number of approaches for treatment, with surgical ventricular restoration (SVR) still among options available for standard of care because it excludes the wall with motion abnormalities and restores left ventricular geometry [Castelvecchio 2016; Zheng 2009; Menicanti 2007]. However, SVR is high-risk, especially due to the higher incidence of postoperative complications and mortality in elderly patients [Wakasa 2014; Hernandez 2006].

Renal dysfunction is a common comorbidity in elderly patients with ischemic cardiomyopathy [Jong 2002; Dries 2000]. Previous studies have shown that renal dysfunction significantly increased the risk of cardiac surgery [Lin 2009; Soltero 2005; Liu 2000]. However, there is limited number of studies focusing on elderly patients with renal dysfunction that received SVR, and a lack of mid-term and long-term follow-up data. In addition, most previous studies used serum creatinine level rather than estimated glomerular filtration rate (eGFR) as the measuring criteria for renal dysfunction, affecting objective assessment of this issue [Hernandez 2006].

This study involved patients with SVR over a 16-year period at a single center. Patients were stratified using eGFR to explore the impact of renal dysfunction on short-term and mid-term outcomes.

\section{METHODS}

\section{Patients}

The data collection procedures are described elsewhere [Hu 2010]. As an overview, from January 1999 to December 2015, 1128 consecutive patients underwent surgical ventricular reconstruction at Fuwai Hospital, Beijing, China, and were considered for the study. Of these patients, 280 with ages more than 65 years were considered "elderly," and were eligible for the study [Li 2008]. Patients were divided into two groups according to eGFR level as calculated by the modification of diet in renal disease (MDRD) equation: those with eGFR $<60 \mathrm{~mL} / \mathrm{min} / 1.73 \mathrm{~m}^{2}$ were considered to have renal dysfunction, and those with eGFR $\geq 60 \mathrm{~mL} / \mathrm{min} / 1.73 \mathrm{~m}^{2}$ were considered to have normal renal function [Levey 2003; National Kidney Foundation 2002; Levey 1999]. GFR $<60$ is equivalent to chronic kidney disease (CKD) stage 3 and higher.

The study protocol was approved by the Institutional Review Board at Fuwai Hospital. Variables and their definitions were similar to those reported in the STS database (http://www.sts.org/). Baseline information related to 
Table 1. Baseline Characteristics

\begin{tabular}{|c|c|c|c|}
\hline Baseline characteristics & $\begin{array}{c}\text { Group } 1 \\
(\mathrm{n}=79)\end{array}$ & $\begin{array}{l}\text { Group } 2 \\
(n=201)\end{array}$ & $P$ \\
\hline Age (year) & $70.5 \pm 3.95$ & $68.7 \pm 3.08$ & .012 \\
\hline Gender (male) & $68.4 \%$ & $79.1 \%$ & .063 \\
\hline Hypertension & $74.7 \%$ & $58.2 \%$ & .013 \\
\hline Hyperlipidemia & $57.0 \%$ & $47.8 \%$ & .185 \\
\hline Diabetes mellitus & $24.1 \%$ & $27.9 \%$ & .552 \\
\hline $\mathrm{BMI}\left(\mathrm{kg} / \mathrm{m}^{2}\right)$ & $23.83 \pm 2.96$ & $24.56 \pm 2.94$ & .066 \\
\hline Smoking history & $45.6 \%$ & $49.8 \%$ & .596 \\
\hline Stroke & $13.9 \%$ & $13.4 \%$ & .914 \\
\hline Previous AF & $12.7 \%$ & $3.5 \%$ & .009 \\
\hline $\mathrm{PCl}$ history & $15.2 \%$ & $15.9 \%$ & .880 \\
\hline CABG history & $0 \%$ & $1.5 \%$ & .275 \\
\hline Previous AMI & $92.4 \%$ & $94 \%$ & .618 \\
\hline Creatinine $\mu \mathrm{mol} / \mathrm{L}$ & $133.84 \pm 38.3$ & $84.44 \pm 14.63$ & $<.0001$ \\
\hline $\operatorname{eGFR}\left(\mathrm{mL} / \mathrm{min} / 1.73 \mathrm{~m}^{2}\right)$ & $47.35 \pm 10.19$ & $81.02 \pm 15.79$ & $<.0001$ \\
\hline NYHA & & & .038 \\
\hline I (\%) & 2.3 & 5.2 & \\
\hline II (\%) & 47.7 & 61.5 & \\
\hline III (\%) & 40.9 & 30.2 & \\
\hline IV (\%) & 9.1 & 3.1 & \\
\hline Involved vessels & & & .650 \\
\hline $0(\%)$ & 1.3 & 0 & \\
\hline $1(\%)$ & 10.3 & 9.5 & \\
\hline $2(\%)$ & 21.8 & 21.5 & \\
\hline $3(\%)$ & 66.7 & 69 & \\
\hline SinoSCORE & $19.2 \pm 1.57$ & $18.8 \pm 1.56$ & .061 \\
\hline \multicolumn{4}{|l|}{ Pre-operative ultrasound } \\
\hline Pre-operative EF (\%) & $42.9 \pm 9.0$ & $46.3 \pm 10.0$ & .014 \\
\hline Pre-operative LVEDD (mm) & $57.8 \pm 7.1$ & $56.9 \pm 7.6$ & .376 \\
\hline Forward flow velocity & $0.76 \pm 0.24$ & $0.78 \pm 0.3$ & .458 \\
\hline
\end{tabular}

Group 1 includes patients with renal dysfunction; Group 2 includes patients without renal dysfunction.

$\mathrm{BMI}$ indicates body mass index; $\mathrm{AF}$, atrial fibrillation; $\mathrm{PCl}$, percutaneous coronary intervention; $C A B G$, coronary artery bypass graft; $A M I$, acute myocardial infarction; eGFR, glomerular filtration rate; NYHA, New York heart association; EF, ejection fraction; LVEDD, left ventricular end diastolic diameter.

personal and clinical characteristics, as well as in-hospital events following surgeries, were complete for all 280 patients involved in the study.

We calculated each patient's SinoSCORE, a risk stratification system developed from the Chinese population, of which the variables include age, chronic obstructive pulmonary disease (COPD), previous heart surgery, ejection fraction, the
Table 2. Intraoperative Characteristics

\begin{tabular}{lccc}
\hline Intra-operative characteristics & $\begin{array}{c}\text { Group 1 } \\
(\mathrm{n}=79)\end{array}$ & $\begin{array}{c}\text { Group 2 } \\
(\mathrm{n}=201)\end{array}$ & $P$ \\
\hline Duration of CPB (min) & $125.1 \pm 63.1$ & $115.0 \pm 41.1$ & .150 \\
Duration for clamping aorta (min) & $81.4 \pm 32.7$ & $76.4 \pm 27.1$ & .219 \\
No. of ITA graft (mean \pm S.D.) & $0.93 \pm 0.26$ & $0.92 \pm 0.27$ & .821 \\
No. of venous distal anastomoses & $1.46 \pm 0.69$ & $1.30 \pm 0.74$ & .104 \\
(mean \pm S.D.) & & & \\
$\quad$ Mitral valve plasty (\%) & 7.6 & 6.0 & .618 \\
$\quad$ Mitral valve replacement (\%) & 3.8 & 0 & .005 \\
Type of SVR & & & .393 \\
$\quad$ Linear plasty (\%) & 50.6 & 48.8 & \\
$\quad$ Modified SVR (\%) & 3.8 & 8.5 & \\
$\quad$ Patch plasty (\%) & 45.6 & 42.8 & \\
\hline
\end{tabular}

Group 1 includes patients with renal dysfunction; Group 2 includes patients without renal dysfunction.

CPB indicates cardiopulmonary bypass; ITA, internal thoracic artery; S.D., standard deviation; SVR, surgical ventricular restoration.

last preoperative creatinine level, emergent/urgent surgery, unstable hemodynamics, congestive heart failure (within two weeks), and myocardial infarction (within three weeks) [Zheng 2013].

\section{Surgical Procedures}

Details of surgical SVR procedures are described elsewhere [Zheng 2009]. As a brief overview, hearts were arrested with antegrade cold blood cardioplegia before the procedures. If concomitant coronary revascularization was to be carried out, all distal anastomoses were performed during the same aortic cross-clamp period and proximal anastomoses were done during the rewarming period. The mitral valve was repaired, when needed, through the ventricular opening with a double-armed stitch at the posterior annulus, from trigone to trigone, and the mitral orifice was undersized with a 28-3024- to 26-mm Hegar sizer. Alternatively, the mitral valve surgeries were done through a trans-atrial septal route when the ventricular opening was not big enough or mitral valve replacement was required.

In our institute, various SVRs were adopted, including standard linear closure, patch repair, and modified ventricular reconstruction, which was developed by our institute [Zheng 2009]. For modified ventricular reconstruction, an incision parallel to the left anterior descending artery was made in the infarcted anterior wall segment. Any thrombus was carefully removed. An endoventricular purse-string suture was placed with a 1-0 prolene line suture. The suture was placed in the scarred tissue above the junctional zone between normal myocardium. The suture was tied, and created an opening of about $2 \mathrm{~cm}$. The ventricular chamber was reduced and kept in satisfactory geometry. The next closure was similar with 
Table 3. In-Hospital Outcomes

\begin{tabular}{lccccc}
\hline & $\begin{array}{c}\text { Group 1 } \\
(\mathrm{n}=79)\end{array}$ & $\begin{array}{c}\text { Group 2 } \\
(\mathrm{n}=201)\end{array}$ & Unadjusted & Adjusted \\
\hline Post-operative complications & 2.5 & 0.5 & .18 & .06 \\
\hline All-cause mortality (\%) & 0 & 1.9 & .55 & .97 \\
Peri-operative MI (\%) & 0 & 1.0 & .99 & .91 \\
Peri-operative stroke (\%) & 5.1 & 0 & $<.01$ & $<.01$ \\
Hemofiltration (\%) & 13.9 & 6.0 & .03 & .04 \\
Mechanical support (\%) & 13.9 & 5 & .02 & .01 \\
IABP (\%) & 1.5 & 0.7 & .99 & .97 \\
ECMO (\%) & 0 & 0.5 & .99 & .99 \\
LVAD (\%) & 86.1 & 74.6 & .04 & .03 \\
Transfusion (\%) & 1.3 & 3.0 & .67 & .26 \\
Re-operation for bleed (\%) & & & & \\
Post-operative ultrasound & & & .02 & N/A \\
Post-operative EF (\%) & $44.5 \pm 8.4$ & $47.0 \pm 9.3$ & .02 & N/A \\
Post-operative LVEDD (mm) & $52.9 \pm 6.6$ & $51.7 \pm 7.0$ & .189 & N/A \\
Forward flow velocity & $0.82 \pm 0.24$ & $0.78 \pm 0.3$ & .133 & \\
\hline
\end{tabular}

Group 1 includes patients with renal dysfunction; Group 2 includes patients without renal dysfunction.

$\mathrm{MI}$ indicates myocardial infarction; IABP, intra-aortic balloon pump; ECMO, extracorporeal membrane oxygenator; LVAD, left ventricular assistant device; EF, ejection fraction; LVEDD, left ventricular end diastolic diameter; $\mathrm{N} / \mathrm{A}$, not applicable.

standard techniques, however, the level of the suture was adjusted continually to keep the ventricle from being distorted during closure.

\section{Mid-Term Follow-Up}

The follow-up protocols are described elsewhere $[\mathrm{Hu}$ 2010]. In brief, all surgical patients discharged alive from hospital were required to return for an outpatient follow-up visit at six months after surgery, and then once or twice each year. In addition, all surviving study participants were contacted by telephone again by the research staff using standard procedures and forms. The overall completion of follow-up information in the current study was $100 \%$. For those who had reported any adverse events after discharge, the medical records in the outpatient clinic were further reviewed for confirmation. If major clinical events occurred and were treated in other hospitals, a copy of relevant medical records were required to be sent back by mail.

\section{Statistical Analysis}

The primary endpoints were all-cause mortality and a composite of midterm effects of the treatment (major adverse cardio-cerebral events [MACCE]), including all-cause death, revascularization, myocardial infarction (MI), or stroke. The secondary endpoints were in-hospital all-cause deaths, MI, stroke, requirement for hemofiltration, and requirement for mechanical
Table 4. Risk Adjusted Mid-Term Outcomes

\begin{tabular}{lccccc}
\hline \multicolumn{7}{c}{ Adjusted analysis* } & & & \\
$\begin{array}{l}\text { Major complications } \\
\text { during follow up }\end{array}$ & $\begin{array}{c}\text { Group 1 } \\
(\mathrm{n}=77)\end{array}$ & $\begin{array}{c}\text { Group 2 } \\
(\mathrm{n}=200)\end{array}$ & $\mathrm{HR}$ & $95 \% \mathrm{Cl}$ & $\mathrm{P}$ \\
\hline MACCE (\%) & $28.6 \%$ & $17.0 \%$ & 2.34 & $1.34-4.08$ & .003 \\
$\begin{array}{l}\text { All-cause mortality (\%) } \\
\text { Newly occurred MI (\%) }\end{array}$ & $16.9 \%$ & $6.0 \%$ & 4.12 & $1.85-9.16$ & .001 \\
$\begin{array}{l}\text { Newly occurred } \\
\text { stroke (\%) }\end{array}$ & $11.7 \%$ & $11.5 \%$ & 1.23 & $0.48-2.67$ & .78 \\
$\begin{array}{l}\text { Repeated } \\
\text { revascularization (\%) }\end{array}$ & $1.3 \%$ & $1.5 \%$ & 1.79 & $0.16-20.19$ & .64 \\
\hline
\end{tabular}

Group 1 includes patients with renal dysfunction; Group 2 includes patients without renal dysfunction.

MACCE indicates major adverse cardio-vascular event; MI, myocardial infarction.

*HR less than 1 in favor of patients with renal dysfunction

supports including intra-aortic balloon pump (IABP), extracorporeal membrane oxygenation (ECMO) and left ventricular assistant device (LVAD). If a similar clinical event occurred more than once in a patient, only the first one was used in analysis.

To minimize potential selection bias, a propensity score analysis was undertaken, for which age and various other baseline variables along with time intervals were used in a logistic regression model to calculate the probability of having renal dysfunction for each patient (Table 1). Risk ratios (RRs) were then estimated using a logistic regression model for inhospital outcomes and a Cox proportional-hazards model for mid-term follow-up data, with eGFR stratification (eGFR < $60 \mathrm{~mL} / \mathrm{min} / 1.73 \mathrm{~m}^{2}$ or eGFR $\geq 60 \mathrm{~mL} / \mathrm{min} / 1.73 \mathrm{~m}^{2}$ ) as the exposure variable; propensity score, year of surgery, and surgeon identities as covariates; and various primary and secondary endpoints as the outcomes. In addition, the Kaplan-Meier method and log-rank test were used to compare the differences in the mid-term outcomes between the two groups.

To help minimize any residual selection bias, an additional propensity score with variables in table 1 along with year of surgery and surgeon identities as covariates was calculated, and a greedy matching algorithm was used to match patients based on the logit of the propensity score with a caliper width of 0.2 of the standard deviation of the logit of the propensity score. For a subset of 154 patients who were discharged alive (77 with renal dysfunction and 77 with normal renal function) and were matched on baseline characteristics, similar analytic procedures were used to examine the differences between the primary end-points. All the statistical analyses were performed using SPSS version 22 (SPSS Inc.).

\section{RESULTS}

\section{Patient Characteristics}

From January 1999 to December 2015, a total of 280 elderly patients underwent SVR and were included in the 
Table 5. Mid-Term Outcomes in Propensity Matched Sample

\begin{tabular}{|c|c|c|c|c|c|}
\hline \multicolumn{6}{|c|}{ Adjusted analysis* } \\
\hline $\begin{array}{l}\text { Major complications } \\
\text { during follow up }\end{array}$ & $\begin{array}{l}\text { Group } 1 \\
(\mathrm{n}=77)\end{array}$ & $\begin{array}{c}\text { Group } 2 \\
(n=77)\end{array}$ & $\mathrm{HR}$ & $95 \% \mathrm{Cl}$ & $P$ \\
\hline MACCE (\%) & $28.6 \%$ & $16.9 \%$ & 2.21 & $1.08-4.50$ & .03 \\
\hline All-cause mortality (\%) & $16.9 \%$ & $3.0 \%$ & 5.73 & $1.62-20.28$ & .007 \\
\hline Newly occurred MI (\%) & $2.6 \%$ & $1.3 \%$ & 2.70 & $0.24-29.84$ & .42 \\
\hline $\begin{array}{l}\text { Newly occurred } \\
\text { stroke (\%) }\end{array}$ & $11.7 \%$ & $13.0 \%$ & 0.92 & $0.34-2.48$ & .87 \\
\hline $\begin{array}{l}\text { Repeated } \\
\text { revascularization (\%) }\end{array}$ & $1.3 \%$ & $1.3 \%$ & 1.20 & $0.07-19.48$ & .90 \\
\hline
\end{tabular}

Group 1 includes patients with renal dysfunction; Group 2 includes patients without renal dysfunction.

MACCE indicates major adverse cardio-vascular event; MI, myocardial infarction.

study. Of all the patients, 79 had an eGFR lower than $60 \mathrm{~mL} /$ $\min / 1.73 \mathrm{~m}^{2}$ and were considered as having renal dysfunction. Patients with renal dysfunction were slightly older than those with normal renal function (70.5 years of age versus 68.7 years of age), but the groups had similar proportions of females, prior history of diabetes, hyperlipidemia, smoking, acute myocardial infarction (AMI), and stroke, as well as mean levels of BMI and previous history of revascularization (Table 1). However, patients with renal dysfunction were more likely to have hypertension, atrial fibrillation (AF), a marginally significantly higher level of SinoSCORE, and significantly lower ejection fraction when compared with patients without renal dysfunction ( $42.9 \%$ versus $46.3 \%$, Table 1$)$.

The duration of cardio-pulmonary bypass and clamping time were not statistically different between the two groups (Table 2). There was also no significant difference between the two groups in the proportion receiving various types of mitral valve surgeries or SVR (Table 2).

\section{In-Hospital Complications}

Table 3 shows the unadjusted and adjusted outcome measures recorded during hospitalization. Overall, the in-hospital mortality was low in both groups, though mortality was higher, with marginal significance, in the renal dysfunction group than in the normal renal function group (adjusted $P$ value $=.06$ ). The need for mechanical supports (adjusted $P$ value $=.04)$ was higher in renal dysfunction group, which was mainly driven by use of IABP (adjusted $P$ value $=.01$ ). In addition, hemofiltration (adjusted $P$ value <.01) and requirements for transfusion (adjusted $P$ value $=.03$ ) were significantly higher in the renal dysfunction group than in the group with normal renal function.

\section{Midterm Outcomes}

There were 77 patients with renal dysfunction and 200 with normal renal function discharged alive. Midterm outcomes are shown in Table 4 and Figure 1. After an average
Supplemental Data: SinoSCORE Risk Factors and Weights

\begin{tabular}{|c|c|c|c|}
\hline Risk factor & Definition & $P$ & Score \\
\hline \multicolumn{4}{|l|}{ Patient-related factors } \\
\hline Age $65-69$ & In years & $<.001$ & 3 \\
\hline $70-74$ & & $<.001$ & 5 \\
\hline$\geq 75$ & & $<.001$ & 6 \\
\hline $\mathrm{BMI} \geq 24$ & BMI & .019 & -2 \\
\hline $\mathrm{BMI}<18$ & & .002 & 5 \\
\hline Chronic renal failure & $\begin{array}{c}\text { Documented past history or } \\
\text { any previous serum creatinine > } \\
176 \mu \mathrm{mol} / \mathrm{L}\end{array}$ & $<.001$ & 6 \\
\hline $\begin{array}{l}\text { Extracardiac } \\
\text { arteriopathy }\end{array}$ & $\begin{array}{l}\text { Any one or more of the follow- } \\
\text { ing: claudication, carotid occlu- } \\
\text { sion or }>50 \% \text { stenosis, previous } \\
\text { or planned intervention on } \\
\text { the abdominal aorta, and limb } \\
\text { arteries or carotids }\end{array}$ & .011 & 5 \\
\hline $\begin{array}{l}\text { Chronic obstructive } \\
\text { pulmonary disease }\end{array}$ & $\begin{array}{l}\text { Long-term use of bronchodila- } \\
\text { tors or steroids for lung disease }\end{array}$ & .024 & 4 \\
\hline NHYA stage III & NHYA definition & $<.001$ & 3 \\
\hline NHYA stage IV & & $<.001$ & 7 \\
\hline \multicolumn{4}{|l|}{ Cardiac factors } \\
\hline $\begin{array}{l}\text { Preoperative atrial } \\
\text { fibrillation or flutter }\end{array}$ & Within 2 weeks & .035 & 2 \\
\hline $\begin{array}{l}\text { Ejection fraction }< \\
50 \%\end{array}$ & $\begin{array}{l}\text { Assessed by echocardiography } \\
\text { (measured before surgery) }\end{array}$ & $<.001$ & 4 \\
\hline $\begin{array}{l}\text { Preoperative critical } \\
\text { stage }\end{array}$ & $\begin{array}{l}\text { Any one or more of the follow- } \\
\text { ing: preoperative cardiogenic } \\
\text { shock, ventricular fibrillation or } \\
\text { flutter, and preoperative IABP } \\
\text { implantation }\end{array}$ & $<.001$ & 4 \\
\hline \multicolumn{4}{|l|}{$\begin{array}{l}\text { Operation-related } \\
\text { factors }\end{array}$} \\
\hline Non-elective surgery & Non-elective procedure & $<.001$ & 5 \\
\hline $\begin{array}{l}\text { Combined valve } \\
\text { surgery }\end{array}$ & $\begin{array}{l}\text { Surgical procedures with either } \\
\text { valve }\end{array}$ & $<.001$ & 4 \\
\hline
\end{tabular}

BMI indicates body-mass index; NYHA, New York Heart Association; IABP, intra-aortic balloon pump.

of 4.1 years of follow-up, a total of 56 patients $(20.2 \%)$ had developed MACCE. Patients with renal dysfunction had an associated higher risk of MACCE than those without renal dysfunction $(\mathrm{HR}=2.34,95 \% \mathrm{CI}=1.34-4.08, P=.003)$. Moreover, mortality was significantly higher in the renal dysfunction group than in the normal renal function group $(\mathrm{HR}=4.12,95 \% \mathrm{CI}=1.85-9.16, P=.001)$. With the exception of revascularization, the rates of various midterm outcome measures were generally higher in renal dysfunction group (Table 4). 
In the propensity score-matched analyses involving 77 patients with renal dysfunction and 77 patients without renal dysfunction, there remained statistically significant 1.21 times $(P=.03)$ and 4.73 times $(P=.007)$ higher rates of MACCE and all-cause deaths in renal dysfunction group than in normal renal function group (Table 5). Similarly, the results for various secondary outcome measures were largely unchanged (Table 5).

\section{DISCUSSION}

SVR is a high-risk procedure. According to data from the Society of Thoracic Surgeons (STS), across the United States, SVR-related mortality reached $9.3 \%$, and postoperative major complication rate reached 33.5\% [Hernandez 2006]. Numerous studies put into question the efficacy of this procedure and caused

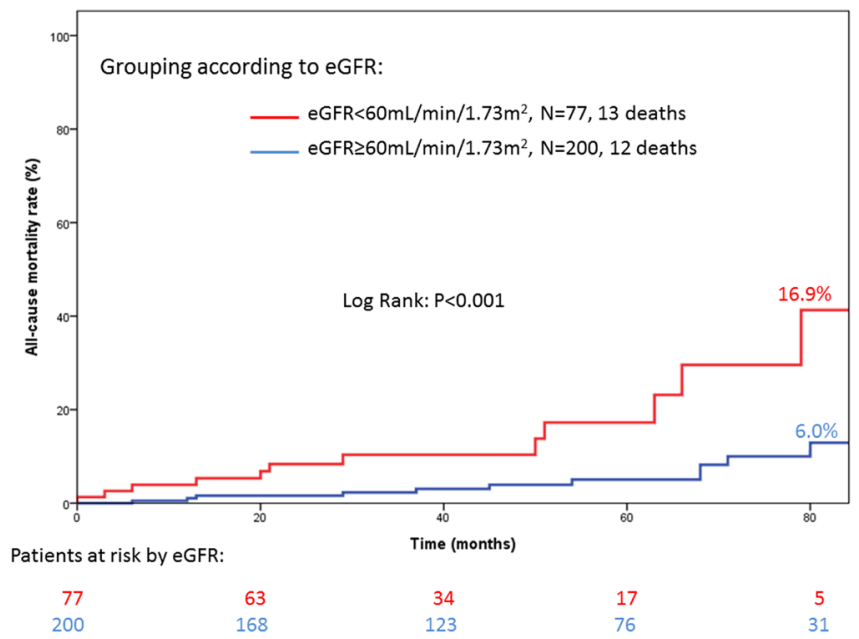

extensive discussion within the community [Michler 2013; Rouleau 2010; Buckberg 2010; Buckberg 2009]. In this context, it has become critically important to explore risk stratification, weigh benefits against risks, and select the appropriate patients.

Our center employed three kinds of SVR. The operation indications were enlarged dyskinetic left ventricle, accompanied by angina and/or heart failure after MI. It may be a concern that different types of surgeries will confound the results. However, our previous single-center study showed that different SVR approaches had no significant impact on the short-term and long-term outcomes under the premises of appropriate indication selections [Zheng 2009]. In addition, in this study there was no significant difference in the distribution of various surgical approaches between the two groups $(P=.39)$. Therefore, we believe that different surgical methods will not affect the results.

Figure 1. Primary endpoints analysis in 280 patients. (A) All-cause mortality rate in follow up. (B) Major adverse cardio-cerebral event (MACCE) rate in follow up.

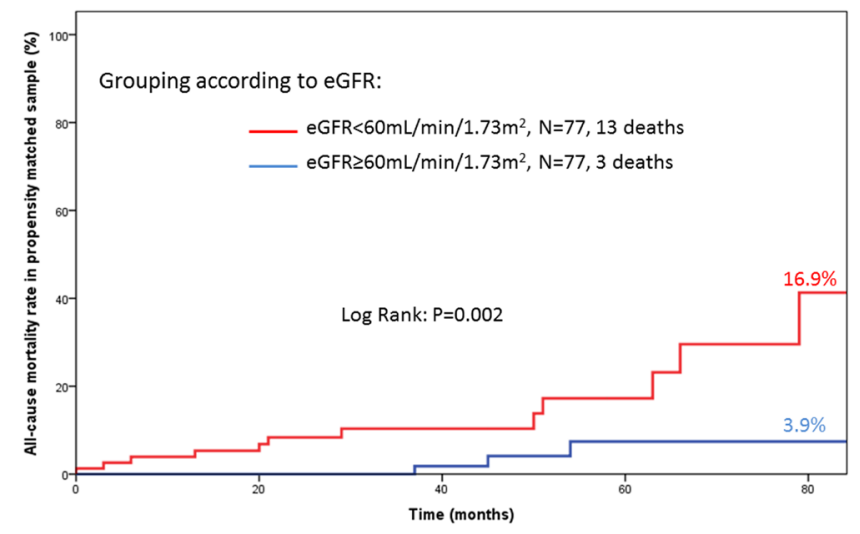

Patients at risk by eGFR:

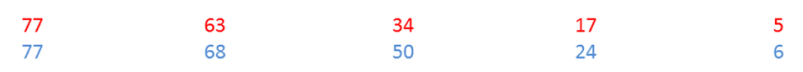

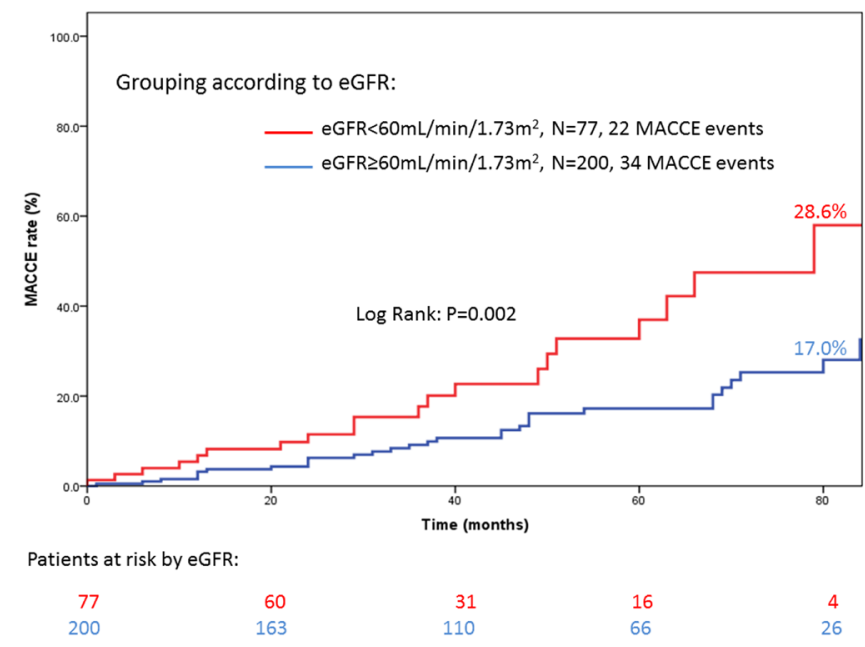

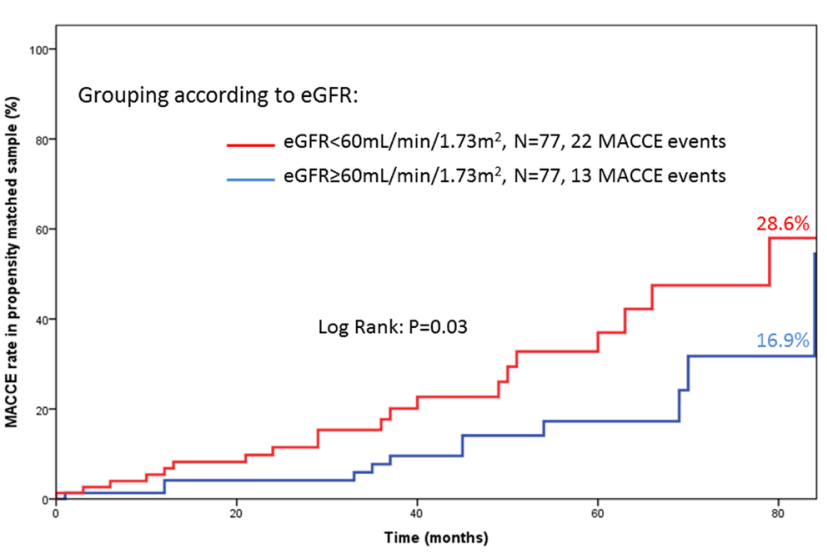

Patients at risk by eGFR:

\begin{tabular}{|c|c|c|}
\hline & $f 0$ & 31 \\
\hline 77 & 66 & 46 \\
\hline
\end{tabular}

Figure 2. Primary end points in propensity matched patients ( $n=154)$. (A) All-cause mortality rate in follow up. (B) MACCE rate in follow up. 
The extent of aneurysm exclusion is always a big concern for cardiac surgeons. Suma et al found in a study involving 107 patients that the long-term survival could be significantly improved by measuring the border of myocardial scar area through preoperative ultrasound and intraoperative direct visualization in order to determine the strategy for surgical approach and extent of exclusion [Suma 2006]. Surgeons in our center adopted a similar strategy for surgical exclusion of infarcted tissue, ie, clearly defining the border of ventricular aneurysm and removing the scar area as far as possible.

In our study, after stratified comparison by eGFR, it was found that the difference of in-hospital mortalities between groups was marginally significant. However, we also found that the needs for IABP and hemodialysis significantly increased in patients with renal dysfunction after surgeries. A possible explanation for this observation might be the fact that a portion of patients in critical status survived the early postoperative period through inotropic and mechanical supports, thanks to the improvements in intensive care managements in the current era. Moreover, our study found that renal dysfunction had a negative impact on the mid-term prognosis in elderly patients after SVR: during the 16-year follow-up period, renal dysfunction was associated with a 1.21 times and 4.73 times higher risk of MACCE and mortality, respectively. This suggests that more aggressive secondary prevention strategies should be chosen for these cohort.

Old age and renal dysfunction are important risk factors for cardiac surgery [Zheng 2013; Nashef 1999]. However, the impact of these two factors on SVR outcomes is unclear. By analyzing the 16-year follow-up data of 280 elderly patients, we found that the incidence of short-term complications significantly increased in patients with renal dysfunction. Furthermore, the incidence of mid-term mortality and MACCE events was significantly higher than in patients with normal renal function.

Among patients with ischemic cardiomyopathy, the proportion of elderly patients is high, and the prognosis is very poor in patients with renal dysfunction [Shafazand 2009; Jong 2002; Dries 2000]. However, studies are still lacking on the efficacy of SVR in patients with old age and renal dysfunction. Wakasa et al found in a multi-center study involving 596 patients that age was an independent short-term and longterm risk factor for postoperative mortality, but this study did not focus on the relationship between renal function and surgical outcomes [Wakasa 2014]. According to a study involving 731 patients with ventricular aneurysm in 141 centers around the United States, the mortality and complication rates in patients with creatinine $>2 \mathrm{mg} / \mathrm{dL}$ were 2.5 times higher than in patients with normal creatinine. However, this study could not objectively reflect the renal function, especially in elderly patients, because creatinine was selected rather than eGFR as the index for renal function [Hernandez 2006]. Moreover, the above studies did not explore the impact of renal function on long-term outcomes of SVR.

\section{Limitations}

This study had several limitations:

1. In this study, we found that patients in the renal dysfunction group were more likely to require IABP support than patients with normal renal function. It is possible that more tenuous hemodynamics underlie this phenomenon, but more data is required to give a plausible explanation for this observation.

2. Although discrepancies exist as for whether patients receiving SVR require revascularization or not, in our center, surgeons sought to guarantee complete revascularization. It might be interesting to see the impact of complete revascularization on elderly patients with renal dysfunctions. However, we only had the number of grafts and whether patients have three, two, or single vessel diseases as variables, so it is impossible to make further comparisons in terms of complete revascularization. In our ongoing studies, we may include more data and make more comprehensive comparisons.

\section{CONCLUSION}

In SVR, patients with old age and renal failure are a highrisk population. This study observed significantly higher incidence of short-term mechanical support, mid-term mortality, and MACCE events. This study suggests the necessity to establish a comprehensive preoperative, intraoperative and postoperative treatment system in order to improve the short-term and mid-term surgical outcomes in these patients.

\section{ACKNOWLEDGEMENT}

We thank Prof. Shengshou Hu, Prof. Jianping Xu, Prof. Yunhu Song, Prof. Hansong Sun, and Prof. Feng Lv, who performed most procedures of the cases in this study.

\section{REFERENCES}

Buckberg GD, Athanasuleas CL. 2009. The STICH trial: misguided conclusions. J Thorac Cardiovasc Surg 138:1060-4 e1062.

Buckberg GD, Athanasuleas CL, Wechsler AS, et al. 2010. The STICH trial unravelled. Eur J Heart Fail 12:1024-7.

Castelvecchio S, Parolari A, Garatti A, et al. 2016. Surgical ventricular restoration plus mitral valve repair in patients with ischaemic heart failure: risk factors for early and mid-term outcomes. Eur J Cardiothorac Surg 49:e72-8; discussion e78-9.

Dries DL, Exner DV, Domanski MJ, et al. 2000. The prognostic implications of renal insufficiency in asymptomatic and symptomatic patients with left ventricular systolic dysfunction. J Am Coll Cardiol 35:681-9.

Hernandez AF, Velazquez EJ, Dullum MK, et al. 2006. Contemporary performance of surgical ventricular restoration procedures: data from the Society of Thoracic Surgeons' National Cardiac Database. Am Heart J 152:494-9

Hu S, Zheng Z, Yuan X, et al. 2010. Increasing long-term major vascular events and resource consumption in patients receiving off-pump coronary artery bypass: a single-center prospective observational study. Circulation 121:1800-8.

Jessup M, Brozena S. Heart failure. 2003. N Engl J Med 348:2007-18.

Jones RH, Velazquez EJ, Michler RE, et al. 2009. Coronary bypass surgery with or without surgical ventricular reconstruction. N Engl J Med 360:1705-17. 
Jong P, Vowinckel E, Liu PP, et al. 2002. Prognosis and determinants of survival in patients newly hospitalized for heart failure: a populationbased study. Arch Intern Med 162:1689-94.

Levey AS, Bosch JP, Lewis JB, et al. 1999. A more accurate method to estimate glomerular filtration rate from serum creatinine: a new prediction equation. Modification of diet in renal disease study group. Ann Intern Med 130:461-70.

Levey AS, Coresh J, Balk E, et al. 2003. National Kidney Foundation practice guidelines for chronic kidney disease: evaluation, classification, and stratification. Ann Intern Med 139:137-47.

Li Y, Zheng Z, Hu S. 2008. Early and long-term outcomes in the elderly: comparison between off-pump and on-pump techniques in 1191 patients undergoing coronary artery bypass grafting. J Thorac Cardiovasc Surg 136:657-64.

Lin Y, Zheng Z, Li Y, et al. 2009. Impact of renal dysfunction on longterm survival after isolated coronary artery bypass surgery. Ann Thorac Surg 87:1079-84.

Liu JY, Birkmeyer NJ, Sanders JH, et al. 2000. Risks of morbidity and mortality in dialysis patients undergoing coronary artery bypass surgery. Northern new england cardiovascular disease study group. Circulation 102:2973-7.

Menicanti L, Castelvecchio S, Ranucci M, et al. 2007. Surgical therapy for ischemic heart failure: single-center experience with surgical anterior ventricular restoration. J Thorac Cardiovasc Surg 134:433-41.

Michler RE, Rouleau JL, Al-Khalidi HR, et al. 2013. Insights from the STICH trial: change in left ventricular size after coronary artery bypass grafting with and without surgical ventricular reconstruction. J Thorac Cardiovasc Surg 146:1139-45 e6.

Moran AE, Forouzanfar MH, Roth GA, et al. 2014. The global burden of ischemic heart disease in 1990 and 2010: the Global Burden of Disease 2010 study. Circulation 129:1493-1501.
Nashef SA, Roques F, Michel P, et al. 1999. European system for cardiac operative risk evaluation (EuroSCORE). Eur J Cardiothorac Surg 16:9-13.

National Kidney Foundation. 2002. K/DOQI clinical practice guidelines for chronic kidney disease: evaluation, classification, and stratification. Am J Kidney Dis 39:S1-266.

Rouleau JL, Michler RE, Velazquez EJ, et al. 2010. The STICH trial: evidence-based conclusions. Eur J Heart Fail 12:1028-30.

Shafazand M, Schaufelberger M, Lappas G, et al. 2009. Survival trends in men and women with heart failure of ischaemic and non-ischaemic origin: data for the period 1987-2003 from the Swedish Hospital Discharge Registry. Eur Heart J 30:671-8.

Soltero ER, Petersen NJ, Earle NR, et al. 2005. Long-term results of coronary artery bypass grafting in patients with ischemic cardiomyopathy: the impact of renal insufficiency and noncardiac vascular disease. J Card Fail 11:206-12.

Suma H, Horii T, Isomura T, et al. 2006. A new concept of ventricular restoration for nonischemic dilated cardiomyopathy. Eur J Cardiothorac Surg 29 Suppl 1:S207-12.

Wakasa S, Matsui Y, Isomura T, et al. 2014. Risk scores for predicting mortality after surgical ventricular reconstruction for ischemic cardiomyopathy: results of a Japanese multicenter study. J Thorac Cardiovasc Surg 147:1868-1874, 1874.e1-2.

Wong CM, Hawkins NM, Petrie MC, et al. 2014. Heart failure in younger patients: the Meta-analysis Global Group in Chronic Heart Failure (MAGGIC). Eur Heart J 35:2714-21.

Zheng Z, Fan H, Feng W, et al. 2009. Surgery of left ventricular aneurysm: a propensity score-matched study of outcomes following different repair techniques. Interact Cardiovasc Thorac Surg 9:431-6.

Zheng Z, Zhang L, Li X, et al. 2013. SinoSCORE: a logistically derived additive prediction model for post-coronary artery bypass grafting inhospital mortality in a Chinese population. Front Med 7:477-85. 